

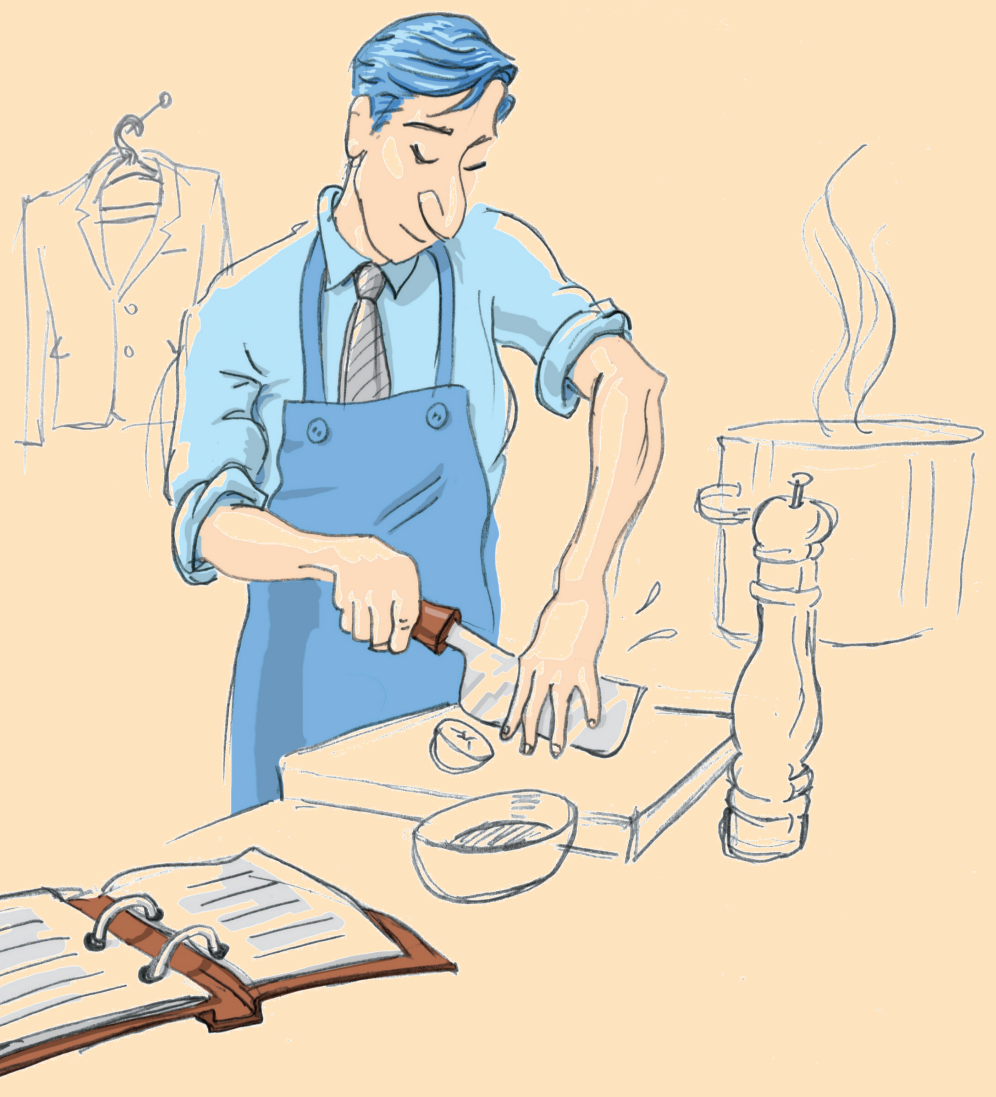




\title{
The Cook
}

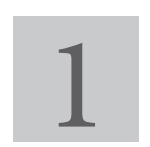

\begin{abstract}
Al my friends are aware that I love to cook; so much so that it has Abecome one of my distinguishing features. During cocktail hour of a conference I once attended with hundreds of business people, an executive - a colleague - introduced me to his acquaintances. As you'd expect, they were standing in a circle holding their wine glasses, engaged in small talk. With some apprehension - as I'm not so great at these events - I slowly walked over, expecting to be presented to these people with my short bio - highlights, title, and a cute anecdote to garnish our new acquaintance. What he chose to do, however, was utterly different. I want you to meet my colleague and friend, he addressed them, you must know, she is such a great cook! I knew then and there that indulging my friends with great dinners is far more impressive than any of my career accomplishments.
\end{abstract}

My annual dinner is a social event for my close friends, and for me it is an adventure in creativity - cooking the meal and putting on the event. These dinners are 6-hours of food samplings and togetherness. A couple of months in advance I set the date and start thinking of the theme for the dinner. I like to tell a story through my choice of theme - usually the experience of a recent trip. I choose around 20 dishes from the typical cuisines of the latest parts of the world where I traveled, such as Tlayuda from a Tianguis in Oaxaca, Tapado soup from a riverside home in Livingston Guatemala accompanied by coconut challah bread from 
the same kitchen, and Secreto cutlets served with rich Mojo Picante from a plancha in the Canaries - yes, they are all served in their refined gourmet versions.

I need to be very careful in selecting the menu for such a long eating event; especially since every dish is accompanied by its matching wine - it has to be light, well balanced, and small, always leaving a taste for more.

I always was very serious about cooking. The French kitchen was my first love. The old French food was exotic, refined, and beyond the grasp of our diaspora-influenced tastes; the dishes left my guests delighted. My first French cookbook, however, was a challenge. In the beginning, whenever a photo seduced me, the recipe had so many steps and unfamiliar terms that I had to shelve it for some time. I didn't fail to produce; rather, I did not make it as a goal to accomplish. Since then, I have mastered the secrets of the French kitchen, but now I have this yearning toward Japanese, which is so delightful and tantalizing on the table, and still unapproachable in the kitchen. At least for me!

In a continuous quest to improve my techniques and delight my friends with surprises, just like Siddhartha's journey toward nirvana, I met my master and mentor somewhere along the way - the Donna Hay magazine. Australia's gift to its western cousins is unjustifiably hardly known outside Down Under. This magazine is so meaningful to me that I prefer to humanize it - we have a relationship. And I continue to be in awe of how much more I can learn from her, like from any good old master. Bite by bite, she augments my vocabulary, enriches the palette of flavors, and with her masterful wisdom she teaches me all the possible shortcuts.

Finally, I found a concise and clear source of variety with global reach, and oh so doable! Now, I can wait much more peacefully for my endless dinners of shock and awe.

In all those years of cooking, I've learned one important lesson for life: great cooking is a craft that grows with experience - not an art. 


\section{The Manager}
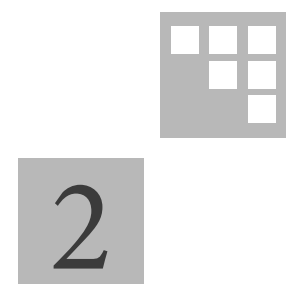

anagement and leadership are also forms of craft - with tools,
methods, ingredients, and techniques that have to be mastered until they are second nature, just as in cooking.

Let's review a wonderful example from The Checklist Manifesto by Atul Gawande, a prominent surgeon and professor at Harvard Medical School. In his book, he offers expertise on how to reduce errors, improve safety, and increase efficiency in surgery - certainly a noble cause - and a story that has direct application to many organizations and fields. The story is simple. During his tenure as Massachusetts General Surgeon, research showed that about $6 \%$ of patients in surgery wards of hospitals developed infections and that the general conditions of these hospitals did not have any effect on this unbecoming statistic. In fact, hospitals in affluent Boston ranked in this research similar to those in India. According to Gawande, the main causal chain was as follows: the surgical environment engenders so much pressure on the medical staff that they make errors in following protective procedures, which in turn leaves the door open for microbes to enter and infect. Clearly, this problem occurred due to the failure of the entire system and not just a failed task.

His approach to solving this systemic problem appears to be very simple; yet, after studying other fields, he proved that using it in his own field is highly effective. A simple checklist, if enforced continually, can reduce 
human error and reverse the hospital infections trend. In his quest to create proper checklists, he found that designing the right checklist was not, however, a simple task; it required special skills and experience - the craft of creating checklists.

Gawande writes that despite these checklists providing an obvious and easy-to-prove positive effect, his major challenge was to overcome the resistance to checklists coming from surgeons. They, the most prominent and confident professionals in a hospital's hierarchy, had a hard time submitting to simple checklists despite the overwhelming evidence of their effectiveness. Conversely, members of the support staff, such as nurses, were far more open to this idea.

Similarly, in my practice, I usually find that managers and leaders are confident that their current toolbox and experience is sufficient for most tasks in their area of responsibility. After all, the fact that they hold the important positions in a group, a unit, a department, or a business is already enough reason for self-assurance. However, after being in quite a few management and executive positions, I know that underneath this confidence lies a great deal of insecurity - the higher the position, the more lonely and insecure one feels. On the one hand, there's nothing wrong with a small dose of paranoia to keep things in balance - I'm certainly not the first to advocate this. On the other hand, I believe that it is important to test this pervasive level of ostensible confidence.

In interviews with managers, I find that they feel confident about being able to execute at least $80 \%$ of their responsibilities in effective and efficient ways. It appears that they have a tolerance for up to $20 \%$ of their work being less defined or in need of revamp. Most managers who have been in their position for some time feel that they have already achieved this $80 / 20$ state $-80 \%$ under control and $20 \%$ less so.

Here is where I like to challenge this view. I find that businesses and work environments are changing at a quick pace. Andy Grove, the legendary chairman of Intel Corporation, said, "leaders have to act more quickly today. The pressure comes much faster." He said this years ago, but it's even 
more relevant today. We see continuous shifts in competitive landscapes and in investors' demands and expectations. Shortages in skilled labor are prevalent. Many companies don't even have fully settled product portfolios or boundaries - product definitions and addressable markets are not constant, not to mention new technologies that make not-so-old ones obsolete at an ever-increasing pace. Managers, especially at middle and lower ranks, are very good at executing tasks, but in these constantly shifting conditions, company structures and management roles are so unstable that they don't achieve their units' best possible contributions to the business. The portion that seems to be under control $-80 \%$ of the manager's responsibilities - is in dire need of reevaluation in many cases that I have reviewed. All aspects of a manager's responsibilities - workload, priorities, human resources, and internal and cross-functional processes should be assessed and corrected at all levels, periodically and not just once.

Why is it, then, that despite hiring educated, experienced, and success-driven people for management positions, we don't see optimal management in the organization? This problem is pervasive and well recognized - executives often report on the shortcomings and subpar performance of their lower management ranks, while conveniently refraining from much self-assessment.

Most of the resumes I review clearly show that people change positions faster than before, whether within their companies or by moving to other companies. Managers who excel in one aspect of their role that's critical to another area of the business are likely to be promoted on a whim without consideration for the entire set of requirements of the new role. A single successful project is often followed by a premature promotion of the "hero" of the project to a higher management position. Looking from top-down, these decisions are hasty; and from bottom-up, the expectations of good performers are also too aggressive - they want to be promoted quickly, and not waste their time.

After such short tenures, it's impossible to attain the level of proficiency that is needed for higher management positions, which is that of a skilled craftsman who is ready to handle complexities, challenges, and changes, 
while driving the unit to meet its full potential for the benefit of the business. We see so much sub-optimal performance, and, yet, managers move from position to position as if they are already masters of their previous roles. They move fast and skip the training opportunities that a job used to provide. The business "chefs" are missing the basic skills of cutting, chopping, mixing, caramelizing, and emulsifying, and yet, they are expected to produce soufflés in an Iron Chef competition.

When I ask managers to define their roles - a straightforward and simple question - many have difficulties answering this and resort to generalities. I've yet to meet a manager who, at first attempt, is able to account for all the functions of his role. I help them with a simple exercise - make a list of all your constituencies and describe in detail the nature of your relationships with them. Typically, with this exercise, the manager develops deeper insight into the breadth and complexity of his responsibilities, and has his original excessive confidence rattled a little.

The comfortable balance of $80 / 20$ - between the larger part of the manager's job that is ostensibly well executed, and the smaller part that requires refinement - does not exist in reality. In most cases, the $80 \%$ needs refactoring before it can be declared stable and ready for regular cycles of improvement. Only when it's well defined and established can the manager focus on the rest, where creativity, art, and inspiration may be applicable.

As a manager, you should never feel totally comfortable; on the contrary, you should periodically assess important high-level questions about your unit and function:

Do we contribute the most to the business?

Is morale at a good level?

- Is everybody working together to attain the best results?

- Do we have the right focus?

- Do other units give us what we need?

- Is it in the format that is best for us? 
- Do we give other units what they need?

- Do we deliver it in the best way for them?

- How connected are we to customers?

- Do we understand the evolution of customer needs?

- Do we know our customers' future demands?

- How much wasteful repeated work occurs?

- Do we balance current needs with future needs?

- Do we provide the correct service levels?

\begin{abstract}
Above all, you need to keep the improvement engine working at all times so that, in the words of Rabindranath Tagore, "the clear stream of reason has not lost its way into the dreary deserts of dead habit."
\end{abstract}

The essence of the manager's role is anchored in these questions. If you still feel relatively comfortable - I think we are about $80 \% \mathrm{OK}$ - use these questions with your constituencies (customers, employees, partners and suppliers) and validate the consistency of the emerging picture. For example, if you are the head of marketing, check that your department's production of sales collateral material (product positioning, website content, presentations) is what the sales representatives need and use. Obviously, your department created the material according to directions from executives in the company, but do field personnel - sales and account managers - use it unmodified and as intended? Or is it only partially useful and off-target for their specific customers? Unfortunately, I see many situations where field personnel spend hours adapting their company's material to their needs while they should be spending these hours converting prospective customers. While both marketing and sales may behave correctly, they follow instructions and make the investment, the result for the company is waste, because of misalignment. This example relates to just one of the questions from the list above - more can be unearthed from digging into them all.

In this book, I've assembled my collection of recipes, checklists, and approaches to management situations and problems. Use them and you will be more comfortable and confident in the $80 \%$. I've been adapting the 
skills and methods to today's ever-shifting requirements, the techniques to the latest management tools, and to the needs of contemporary generations of workers. I've been refining, using, and teaching them over the last 30 years in many types of businesses, industries, and organizations. These are not groundbreaking theories; rather, you'll find elegant recipes that work, and you will understand why they work!

We will work together - you and I - on techniques to deal with large and small tasks. We will follow a process to create a strategy and keep it updated; we will learn what to consider for organizational structure and how and when to reorganize. We will also look at smaller work items, such as creating and driving a program, setting goals, interviewing, assigning tasks, and even how to efficiently write an effective email.

These recipes are simple and linear, with as few steps as possible. Obviously, you have to adjust them to your situation; the effort will contribute toward making an organization more effective and more efficient, which is an organization that produces the intended results and increases productivity by eliminating clutter and waste. 


\section{The Cookbook}

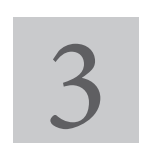

The key to organizational success in a chaotic world is to ensure that we are not adding to the chaos, but rather, are finding ways to reduce it. Well-meaning managers often create and execute appropriate actions; however, I often see decisions that are not followed thoroughly and consistently. Adherence to a new cross-functional process, for example, quite often remains in a state of flux or disappears altogether once it hits its first difficulty. Before starting a process, procedure, or initiating any kind of reorganization, spend time discussing it with all involved in the activity and elicit their commitment to adopt it religiously — something which they cannot ignore or neglect. Address every difficulty with a commitment to improve the process until it's stable. Change always comes with a productivity price - friction and unexpected obstacles are natural. Without commitment to bring the change to a conclusive, stable state, the original problems persist and the organization continues to pay the price.

We, in business, cannot allow the high level of waste that exists in institutions such as in government. Cabinet Secretaries or Ministers make decisions, but a very small percentage of them are followed as intended. In good cases, results come after delays or with budget overruns. I know of one government controller who claimed that there was only a consistent $20 \%$ rate of follow-through on ministerial decisions. He didn't claim any bad intentions; it's just that these decisions were made without 
12 For God's Sake: Work by the Book - Management Explained from Within

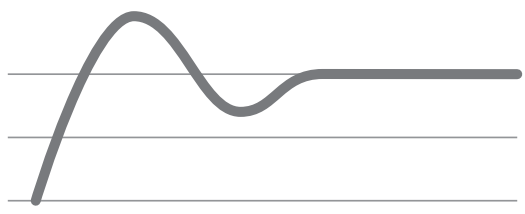

Continous Improvement Lasts

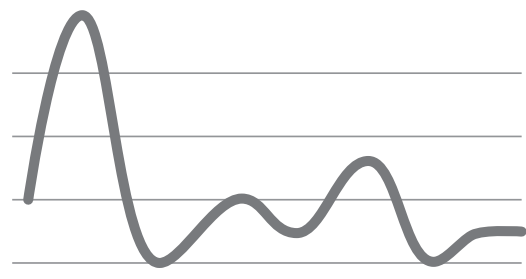

One Time Fix Disappears

Figure 1

checking feasibility, and the high turnover in political positions did not allow enough time for developing the experience to execute decisions properly. With such low performance, we would see our businesses die while these ministers can stick around until the next election.

The manager's job is never easy, and it's not meant to feel natural. The approaches, techniques, and tools that I cover in this managers' cookbook will help you make good and thorough decisions, and stick to them (Figure 1). By mastering these techniques, you will improve the $80 / 20$ to $80 / 20 / 20-80 \%$ of your responsibilities executed with $20 / 20$ vision. It's within a manager's reach if he takes his job seriously. 